University of Minnesota Morris Digital Well

University of Minnesota Morris Digital Well

$11-26-2016$

\title{
Teaching in the Cracks: Using Familiar Pedagogy to Advance LGBTQ-Inclusive Curriculum
}

\author{
Michelle L. Page \\ University of Minnesota - Morris, pagem@morris.umn.edu
}

Follow this and additional works at: https://digitalcommons.morris.umn.edu/education

Part of the Curriculum and Instruction Commons, and the Language and Literacy Education Commons

\section{Recommended Citation}

Page, Michelle L., "Teaching in the Cracks: Using Familiar Pedagogy to Advance LGBTQ-Inclusive Curriculum" (2016). Education Publications. 2.

https://digitalcommons.morris.umn.edu/education/2

This Article is brought to you for free and open access by the Faculty and Staff Scholarship at University of Minnesota Morris Digital Well. It has been accepted for inclusion in Education Publications by an authorized administrator of University of Minnesota Morris Digital Well. For more information, please contact skulann@morris.umn.edu. 
Teaching in the Cracks: Using Familiar Pedagogy to Advance LGBTQ-Inclusive Curriculum 


\begin{abstract}
English/Language Arts (ELA) teachers and other literacy educators have the opportunity to create more positive and more inclusive school experiences for gender and sexual minority students, but many hesitate to transform their curricula and practices due to fear of community protest. To support educators who feel vulnerable or constrained, this article summarizes challenges facing gender and sexual minority students and then describes the benefits and limitations of a variety of familiar instructional approaches that teachers can use to make curricula more inclusive, ultimately reducing isolation and invisibility of LGBTQIA students and experiences.
\end{abstract}




\section{TEASER TEXT:}

- Familiar teaching practices can help ELA teachers to become change agents in their classrooms and offer support to LGBTQIA students.

Teaching in the Cracks: Using Familiar Pedagogy to Advance LGBTQ-Inclusive Curriculum

In this community, I am fairly certain that using literature with GLBT themes would upset many parents and potentially cause me to lose my job. It is one of the reasons I feel a little uncomfortable in this district. I believe that curriculum should address these voices instead of silencing them, but I'm not sure I'm brave enough to deal with $90 \%$ of my students' parents being angry with me. "Sandy," rural teacher

Many English/Language Arts (ELA) teachers, like Sandy, are nervous about including gender and sexual minority themes and experiences in their curricula. Teachers in rural districts can feel particularly vulnerable (Page, 2014; Page, under review). I assert that we must take teachers' fears seriously rather than dismiss them. In this article, I describe familiar teaching approaches and how they can be used to cultivate greater curricular inclusion in the classroom. Other literacy mentors may also benefit from thinking about everyday practices that can be used to include all students. Whether literacy practices are cultivated in a traditional classroom, in the community, within organizations, or within homes, inclusion of diverse texts is an imperative step in building a critical literacy.

No term seems adequately broad to capture the diversity of identities people hold. In this piece, in an attempt at inclusivity, I use multiple terms interchangeably. I use the term "gender 
and sexual minority" to discuss multiple identity labels which are not heterosexual and/or cisgender (when one's gender identity conforms to their sex assigned at birth). Likewise, I use the term "queer" to encompass a broad range of identities and convey the diversity of ways in which individuals identify themselves. Finally, I will also use "LGBTQIA" to denote lesbian, gay, bisexual, transgender, queer or questioning, intersex, or asexual identities. Where other literature is cited, I will use the authors' terms (such as "LGBT").

The Need for Inclusion: Impacts of Negative Climate

Teachers are unified in their desire to educate students effectively, to help students feel comfortable and safe in school, and to provide all students the opportunity to learn. However, not all students are having the experiences that teachers hope for them. Specifically, gender and sexual minority students feel less safe, less engaged, less respected, and less valued in our schools than do their heterosexual and/or cisgender identified peers (Kosciw et al., 2014; Lecesne, 2012; Robinson \& Espelage, 2011). Additional studies reveal high levels of suicidal ideation, peer rejection, and harassment of students by teachers (Robinson \& Espelage, 2011).

Negative school climate is correlated to negative academic outcomes. One study found that $22 \%$ of LGBTQ middle schoolers were already skipping school and feeling a lack of belonging in school (Robinson \& Espelage, 2011), while the National School Climate Survey (NCSC) showed that negative school climate resulted in a higher proportion of LGBT students dropping out of school and skipping school (61\% vs. 17\%), lower grade point averages for harassed students (2.9 vs. 3.3), and significantly lower rates of post-secondary education aspirations (Kosciw et al., 2014, p. xviii). 
Gender and sexual minority students face many challenges, including victimization in school. However, evidence suggests that bullying alone may not fully account for the psychological and educational risks experienced by LGBTQ students. Robinson and Espelage (2012) found that LGBTQ students experiences higher levels of risk even when researchers controlled for differences in victimization. LGBTQ students experienced more suicidal ideation, suicide attempts, and truancy than their heterosexual and cisgender peers who experienced equivalent levels of victimization (p. 309). Investigators concluded that some of the risks/disparities could be attributed to "stigmatizing, macro-level messages...that persist even in the absence of direct individual-level peer victimization" (p. 316).

One of the greatest traumas that gender and sexual minority students experience is not bullying but invisibility and silence. When queer students are not visible in the curriculum or in the social networks of school, when the school is silent about their experience, this creates feelings of disenfranchisement and rejection—it creates a "stigmatizing message" that these students are not valued. Students' identities are erased and invalidated.

In one study (Page, 2016), LGBTQIA students were asked about their most negative school experiences. Of over 20 participants, all except one cited their schools' silence around queer issues as the most negative and impactful experience they had. When asked about their most painful experience, "M.J." states, for example, "It's really hard because you know it [LGBTQ issues] wasn't even mentioned ever. It was such a deep silence. Like, there was just nothing....I can't even think of any time that it was even brought up....Like the slurs, and as people make fun of each other, it's there — but worse, it just wasn't even talked about. Not even talked about. Like it's nothing." (Note that all names are pseudonynms.) 
Research suggests that creating a positive school environment for LGBTQIA students is imperative. One key resource that increases visibility, provides a sense of belonging, and makes a difference in the school lives of LGBT youth is queer-inclusive curriculum; yet only $18.5 \%$ of students experience inclusive curriculum, according to the NSCS (Kosciw et al, 2014, p. xix). This is compounded by a dearth of resources that might supplement curriculum and enhance visibility (e.g., library holdings, access to online resources).

$\underline{\text { Impacts of Positive Queer Inclusion }}$

Literacy educators have the opportunity to make a difference in the lives of queeridentifying students and to help stem the tide of harassment, violence, depression, and other issues often experienced by gender and sexual minority learners.

Inclusive curriculum can have a large impact. Where inclusive curriculum is used, LGBT students experience less absenteeism, more connection to their schools, and greater acceptance from their peers (GLSEN, 2011; Kosciw et al., 2014). Inclusive curriculum can also lead to a greater perception of safety (Toomey et al., 2012; Russell et al., 2006; O'Shaughnessey et al., 2004) and reduced homophobia (Knotts and Gregorio, 2011).

Educators and others are beginning to address the dearth of queer young adult literature and resources to support its use in classrooms. Publication of LGBTQIA literature, particularly for the young adult market, has increased (Emert, 2013; Cart \& Jenkins, 2015) and texts on academic freedom and censorship have been published (e.g., Biegel, 2010; Curwood, Schliesman, \& Horning, 2009; Lent \& Pipkin, 2013). But if teachers are to fulfill our responsibility to teach all students and to support all students' academic potential, we must do more. Mayo (2009) states, "There is a loud silence in curricula that indicates to all students that 
there are some people in the school who do not deserve to be spoken about and that even some interested in protecting sexual minority youth appear willing to use a community agreement on civil silence as protection" (p. 267). Queer literature includes LGBTQIA youth in the curriculum and shows them that they are not alone; the silence becomes less thunderous.

\section{The Status of Inclusive Curriculum: Reports from the Field}

The literature suggests that sexual minority students can benefit from teachers utilizing queer-inclusive curriculum. Yet, in students' perception, few teachers are doing so (Kosciw et al, 2014). This finding is confirmed by other research (Page, 2014; Page, under review) which found that many educators, particularly those in rural areas who feel vulnerable to community attack, hesitate to transform their curricula to be more inclusive, fearing gas lighting, ostracism, and job loss.

Recently, I had a conversation with a colleague about this phenomenon. "Pfft," she snorted, waggling her fingers, "there are tons of resources on academic freedom and censorship — they just need to use them!" In essence, my colleague implied that teachers' fears were "old news" and "not a big deal." But researchers, teacher educators, professional development experts, and colleague instructors do teachers a disservice if we dismiss their concerns.

There is a disjuncture between people like my colleague and many teachers in the field. To my colleague, it appears that there are many resources available to teachers related to inclusive curriculum (for example, the 2015 conference of the National Council of Teachers of English included 18 sessions that addressed LGBTQIA themes). But resources alone do not eliminate risk - and many teachers cannot or do not attend such a professional gathering. How 
can we support their work? Literacy educators face a wide array of opportunities and challenges, depending on their circumstances. To bridge this divide, I hope to help educators think about familiar instructional techniques in new ways, with the goal of including diverse gender and sexual identities into the curriculum.

\section{Familiar Pedagogy, New Goals}

If educators care about concepts such as justice and fairness, the texts we use matter; it is fundamentally neither just nor equitable for some students to be erased from the curriculum. One of the ways that schools tacitly condone homophobia is by failing to include queer literature in the curriculum (Curwood et al., 2009). Invisibility is, in effect, invalidation, as McLean (1997) reminds us: “Ignoring or denial of a group's existence in literature invalidates the experience and self-identity of members of that group by rendering them invisible, not only to themselves, but to all other groups in a society" (p. 182).

Though there is evidence that the goal of inclusive curriculum is not being achieved (Kosciw et al., 2014; Page, 2014; Page, under review), there are teachers like "Sandy" who want to be allies to their LGBTQIA students and want to implement inclusive curriculum but are intimidated by the prospect. To them, I say that there are few completely closed systems - there are almost always cracks. Where is the open space in curriculum and pedagogy—where are the cracks - through which we might work toward equity? Perhaps one of the challenges for any educator is to identify the cracks and then do what we can in that space, like the plant growing up through the sidewalk.

I present below several options for how to integrate queer-inclusive texts and curriculum in the classroom. Many teachers, even those who are fearful or feel constrained, may be able to 
implement at least one of these approaches - we can each find our crack to exploit. Sometimes one needs to focus on what one can do and take those steps rather than focus on what one can't do (at least, not yet). Such steps can puncture the "official silence [that] makes schools hostile places for sexual minority youth and any youth perceived to be a sexual minority" (Mayo, 2009, p. 268). By utilizing the following approaches, teachers can move from exclusionary "business as usual" curriculum toward an inclusive, queer pedagogy which challenges and decenters binaries and norms.

Moving Across the Axes

I conceptualize two axes to frame one's approach to queer-inclusive curriculum (see Figure 1). Teachers can use these axes to consider their own goals and circumstances in choosing instructional approaches. The visibility (public/private) axis has to do with how open teachers are in featuring LGBTQIA texts, characters and issues in their classes. How large of an "audience" is there for these texts? Is the whole class exposed to these texts and ideas or only a small portion? How public is the teacher's stance? The inclusion axis (saturation) maps how thoroughly queer texts are integrated. Are they not included at all? Included only in "special" units? Included throughout a course of study, in every unit? None of the approaches I will discuss is new; they are discussed to assist teachers who feel constrained or vulnerable but who wish to be allies to the queer community. Just as Gloria Ladson-Billings characterizes culturally responsive pedagogy as "just good teaching," so too can "just good teaching" result in a more inclusive educational experience for LGBTQIA students (Ladson-Billings, 1995).

[Figure 1. Schematic of Approaches to Queer-Inclusive Curriculum] 


\section{$\underline{\text { Partial Visibility }}$}

Many educators make time for reading in class and encourage reading for pleasure outside of class. One approach to integrating LGBTQ literature is to work with the librarian/media specialist to include such choices in the school library and to include such texts in classroom libraries (particularly important for those teachers/schools who lack a professional librarian). Student choice reading encompasses the left side of the chart as it relies on individual student choices that may not be very visible.

Depending on available reading options, choice reading can vary in its level of inclusivity. Ideally, all menus and reading lists include queer texts. Whether the instructor explicitly discusses reading choices with students or implicitly reveals what is available through a potential reading list, ultimately students make the decisions in choice reading activities. This approach is often more comfortable for teachers. Indeed, teachers in one study displayed the highest level of comfort with LGBTQ texts when using them for student pleasure or choice reading (Page, 2014; Page, under review). Choice reading may also allow inclusion of texts that teachers might not feel comfortable using for whole-class units due to sexual content, violence, or other mature themes.

One benefit of student choice reading is that nearly any text can be used-the goal is for students to enjoy reading it. A few favorites of students I've worked with also will be mentioned in upcoming sections_-The Perks of Being a Wallflower, Hard Love, Boy Meets Boy, Will Grayson Will Grayson, and Ask the Passengers.

A constraint of this approach is that it places the onus of text selection on the student--not all students may feel comfortable being seen by parents or peers as having chosen a queer text. 
Also, while the visibility of LGBTQ literature as a choice reading may contribute to creating a safer and more welcoming environment for LGBTQ students and may help to promote acceptance among all students, it still places queer literature in the margins rather than as a central part of the curriculum.

\section{Constrained Visibility}

Literature circles or book clubs are helpful methods when one wishes to diversity curriculum but lacks the confidence or resources to engage in a fuller transformation. When an instructor uses literature circles or book clubs, typically they select several texts and then allow students to choose from among them, forming study groups centered on those texts. This approach provides greater visibility for queer texts - typically teachers "book talk" the texts to introduce them and students read texts in groups rather than individually.

Curriculum integration varies according to how broad or narrow the theme and text selection. A teacher may utilize an entire set of queer readings, but it is more common to use a broad theme (such as diversity, friendship or coming of age) and to include at least one reading choice with gender and sexual minority characters. Because only a sub-set of the class engages with a queer text, I consider this approach to be "constrained" in its visibility.

Like choice reading, a literature circle or book club may not result in questioning binaries or decentering heteronormativity. However, using literature circles and book clubs that include queer texts sends a positive message, as the teacher has chosen this set of texts and is sanctioning them for classroom use. Additionally, the teacher has created space in the classroom for students to talk with each other about these texts, thus diminishing the silence that often surrounds 
LGBTQIA issues in schools. Many book clubs are centered on themes--some ideas for themes and texts are included in upcoming sections.

Visible with Partial Integration (Diffused Focus)

Visibility of LGBTQ literature can be heightened by including queer texts in whole-class units of instruction. Generally, teachers who feel more vulnerable might focus on topics which are not explicitly or solely queer, including some texts with LGBTQIA characters or issues, but having the explicit focus of the unit be on a "universalized" theme. Or, texts might include queer characters or storylines but in a supporting role, with the primary story following a theme or plot line such as human against nature, solving a mystery or problem, or power and totalitarianism, for example. Units on family, friendship, or romance are common.

Sometimes people who have not read much LGBTQ literature believe that such texts contain a great deal of sexual content, but this is not the case; situating the literature within a context of a variety of relationships and storylines might eliminate this notion.

Like book clubs, a skills-based or standards-based approach can heighten visibility, even as it disperses the focus. Here, one explicitly focuses on a skill or standard, such as assessing "how point of view or purpose shapes the content and style of a text" (Common Core Anchor Standards CCRA.R.6). The texts may incorporate LGBTQIA characters or storylines but the teacher neither emphasizes nor excludes these; rather, the teacher a particular literary analysis skill or writing skill is emphasized.

For an international literature study (CCSS.ELA-LITERACY.R19-10.6) one might include If You Could be Mine, set in Iran. One could do a genre study and use More than This or Diverse Energies as science fiction examples or teach a poetry unit that includes October 
Mourning. When studying magical realism, Weetzie Bat might serve as an example. Alternative formats and visual literacy could be explored using Hard Love (which uses zine formats) as a jumping off point; or graphic novels such as Skim or Pedro and Me or Stuck Rubber Baby could be used. A Holocaust unit might be enhanced by selections from Branded by the Pink Triangle or a unit on identity and labeling could include Openly Straight. Consult the Recommended Reading (linked in "More to Explore") for text titles, genres, and themes/subjects.

Teaching about censorship or academic freedom also highlights queer literature. Here, one could examine the many reasons why literature is challenged and read selections from texts that represent these challenges. Students could analyze and discuss the foundation of the challenge and offer opinions about whether such texts should be challenged or not. Thus, the teacher can explicitly address LGBTQ literature and issues under the umbrella of censorship and can create a launching pad for discussions with students, parents, and community members about the value of literature.

The censorship unit makes queer literature more visible since the whole class reads these selections, but integration may be partial as the unit also focuses on other reasons that literature is challenged (the focus is more diffused). Texts with queer content that appear on the American Library Association's most challenged lists include The Perks of Being a Wallflower, Rainbow Boys, Athletic Shorts, The Color Purple, Annie on my Mind and others.

Teachers should be intentional in crafting censorship or other units; having a more diffused focus may present the impression that the teacher is hiding or "sneaking in" queer literature, like a parent hiding a child's vegetables in a favorite food. This may inadvertently send a message of shame or fear. Nonetheless, positive inclusion (even if subtle) is preferable to invisibility. 
There are many benefits to using unit- and skills-based approaches. If a teacher is challenged, alternative texts are easily substituted. Including queer texts and ideas in a subtle way can have a normalizing effect, which benefits all students. In a unit on romance, or family, for example, students can see same-sex relationships as equal to (rather than deviant from) heterosexual relationships. Queer themes and texts are clearly supported by teachers when used in these units—queer texts are not singled out as "dangerous" texts.

\section{Visible with Partial Integration (Concentrated Focus)}

Some have diversified their curriculum and pedagogy by "queering the classics" or engaging the "closeted canon." This does not mean that the teacher forces an artificially queer lens onto texts, but rather such information is allowed into the classroom and is not silenced. The queering the classics approach engages students in reading classic texts (The Great Gatsby, Catcher in the Rye, A Separate Peace, Greek mythology, etc.) or authors that are often an established part of the curriculum (for example, Walt Whitman, Oscar Wilde, Emily Dickinson, James Baldwin, Virginia Woolf, Willa Cather, Shakespeare).

In teaching the texts, the instructor examines LGBTQIA themes that may be present in the literature and/or the instructor engages students in examining the text from a variety of angles, including an angle of sexuality and/or gender and/or gender identity and expression; the teacher also includes information about the author's sexual orientation or presumed sexual orientation and gender/gender identity. For example, Walt Whitman's “The Wound-Dresser" includes language that some modern readers might take to be homoerotic when he speaks of loving the wounded soldiers. Teachers might discuss this with students- $\underline{\text { is }}$ the language homoerotic? Why or why not? How does the historical and social context of the poem and 
reader impact interpretation? Does Whitman's gender impact how we interpret the poem? If we presume Whitman to be gay, does this impact our reading? What if we presume him to be straight? Does it matter and why or why not?

Instructors employing this approach might question how a reader's understanding of or presumption about an author's sexual orientation or gender identity affects the reading and interpretation of the text. Likewise, the class might explore how that aspect of an author's identity or his or her experience shapes the narrative, structure, or theme of the text. The historical and cultural context of the texts and author might also be relevant information to share with students (for example, the concept of "romantic friendship" and how that concept is exemplified in Dickinson's works (see Comment, 2009) or compulsory heterosexuality in Romeo and Juliet (see Ressler, 2005)).

The idea is not to focus on LGBTQIA themes and ideas to the exclusion of other aspects of the literature, but to include these aspects as important complements that can deepen the understanding of the texts (Comment, 2009, p. 66). The LGBTQ elements of the work or of the author's life are not left invisible or presented as something abnormal, but rather integrated as one of many facets that deserve exploration and interpretation.

Here, while the curriculum itself may not be transformed to include explicitly queer texts, how the curriculum is examined and the focus of the teacher's pedagogy has the effect of curriculum integration even if the curriculum, on its surface, appears unchanged. The way we read is as important as what we read. Additionally, visibility is high as the entire group or class engages in this type of inquiry.

Full Visibility and Integration: Transformation and Alchemy 
The highest levels of visibility and/or transformation of curriculum requires infusing queer theory and pedagogy into the classroom. Queer theory and pedagogy examine how identities and realities are constructed, both socially and linguistically. These theories also challenge the deeply engrained and societally persistent male-female and gay-straight binaries, considering identities as "continually negotiated and always under construction" (Letts, 2002, p. 126). Critical examination is also brought to bear on social and material power and oppression. By identifying how power is created, gathered, and used, students can challenge that power and alter social and structural realities and disrupt oppression (Britzman, 1995, pp. 152-153). Teachers employing queer pedagogy have an activist, critical, social justice stance. While educators of older students may be able to more explicitly include complex literary theories, critical literacy and an activist stance can be modeled at all developmental levels.

Teachers who use a queer pedagogy not only ensure that their curriculum and text selection are inclusive throughout the course of study, they also explicitly engage lenses of gender, sexuality, intersectionality, and power. They attempt to disrupt heteronormativity which privileges and normalizes heterosexuality. For example, teachers could use problem- and question-posing strategies to explode these binaries, such as: "What elements of the text can be perceived as being masculine (active, powerful) and feminine (passive, marginalized) and how do the characters support these traditional roles?" and "Where do the ideas of masculine=powerful and feminine=passive come from?" and "What sort of support (if any) is given to elements or characters who question the masculine/feminine binary? What happens to those elements/characters?" and "How is queer, gay, or lesbian experience coded in texts that are by writers who are (self) identified as LGBTQIA?” (see Brieze et al., 2010, for more ideas). 
A lesson that interrogates gender binaries is one way to begin to engage queer theory. The text Brooklyn Burning, for example, never names the gender or sexual orientation of the main speaker. The narrator addresses a "you" whose gender and sexuality also remain unnamed. The discomfort this often causes among readers can serve as a tool to question binaries and labels altogether. Why are these so powerful? Who gains and loses when such binaries are enforced? How do labels and binary systems relate to systems of power in our society? The text can help frame a deeper discussion that asks students to look at the world differently — to queer their reading.

Reading LGBTQ texts as a class rather than as individuals yields conversations that usually don't happen in individual reading. By interrogating texts via queer pedagogy, instructors can unveil heteronormative practices that permeate texts, society, and schools and can apply critical perspectives to all literature, not just literature containing LGBTQIA characters and storylines. In this way, students and their schooling experiences can be radically changed.

Teachers using queer pedagogy understand that while it is important to diversify what we read, how we read is just as important and they lead students in examining literature in critical ways. Winans (2006) states that “... simply adding materials about 'the other' does not challenge our pedagogy or conceptual framework in meaningful ways; the additive approach of inclusivity or celebration of difference tends to leave dominant cultural assumptions and their complex relationships to power unexamined" (p. 104).

As Winans (2006) suggests, exposure to LGBTQ literature is usually not enough to challenge or penetrate the permeating heteronormativity found in schools and society. Adding queer literature to the English/Language Arts curriculum is an important part of creating equitable representation of gender and sexual minority students, but such inclusion in and of 
itself will not necessarily change the status quo: ultimately, we must not only add to the curriculum, but we must seek to transform it. Teachers who queer the curriculum engage in alchemy, turning business as usual into gold.

\section{Conclusion}

If all students are to be included and valued in schools, educators must address issues of sexual orientation and gender identity in the curriculum. Educators are responsible to prepare all of our students to live in a diverse society and to create safe spaces for all students. We cannot do this by erasing people, ideas, or language from the curriculum to spare ourselves from conflict that might never occur. Curwood et al. (2009) remind us,

Teachers who approach selection reactively can become mired in 'what if' scenarios that leave them second-guessing, agonizing, and rejecting anything they think is unsafe. (The irony being, of course, that there is no such thing as a truly 'safe' book.) It's a miserable, untenable position for any teacher to be in. Denying students the opportunity to read works because of 'what might happen' turns all power over to an imagined 'someone.' The would-be censor doesn't necessarily have a name-may not even exist. Censorship —in the form of self-censorship — has already occurred (p. 40).

The invisibility and silencing that result from censorship and self-censorship perpetuate negative messages about LGBTQIA students, advancing a hidden curriculum of intolerance and heteronormativity that, in effect, erases the existence of some of our students. Educators must find ways to fulfill our responsibility to affirm students' selves.

But not every teacher inhabits a context where they are safe to fully engage a queer pedagogy or fully integrate their curriculum. Some are not safe to express their own sexual or 
gender identities. For those teachers, considering the levels of visibility and inclusion that are possible in their schools might enable them to use familiar instructional approaches to lay the groundwork for even greater integration in the future. By using familiar models to incrementally modify their curriculum and pedagogical approaches, they can shift the community culture and expectations; they can create a "new normal." They become the forceful seedling bursting up through the cracks in the concrete.

We will make greater gains if all literacy educators, regardless of context, join together. We must better prepare preservice teachers for conversations about academic freedom, offer accessible opportunities for in-service teachers to develop their knowledge of queer pedagogy, create and support GSA's and other groups, and advocate for libraries and research centers and community organizations that support sexual and gender minority students. Guidelines and rationales for literary texts could be provided free of charge by professional organizations. Educational leadership organizations should provide support to principals and superintendents so that they can be advocates for all teachers and students.

Future research that explores how to help teachers reduce their fear and discomfort and increase their efficacy is required. Community- and school-based educators are powerful resources for students who are often invisible, marginalized and alienated in schools, but they must be equipped with tools, ideas, and allies that will help them to feel empowered so that they, in turn, can empower their students.

In Neil Gaiman's The Graveyard Book, Nehemiah Trott says to the young protagonist, "If you dare nothing, then when the day is over, nothing is all you will have gained." This is a lesson for educators as well. If we dare nothing, if we make no effort toward change, there will be no gains. The gains we hope to make are not just for us, but for our students in their 
academic and personal growth. If we believe that all readers benefit from reading realistic literature that represents the range of humanity, then our actions, however small or large, are worthwhile. Perhaps one day every student will see themselves reflected in the curriculum and will feel welcome and valued. But such change does not happen without teachers who dare to teach in the cracks — and break them wide open.

\section{TAKE ACTION!}

1. Evaluate your community climate - how open is your school and community? Are your perceptions based on concrete incidents of inclusion or exclusion or are they assumptions?

2. Gather your allies. Who in your community would support you in your endeavors? Are there other teachers with whom you are in contact in your region or online? What organizations can help you?

3. Review your school's policies on text challenges. If the policies are inappropriate or nonexistent, gather your allies to assist in creating or changing them.

4. Create rationales for the texts you want to use. Don't self-censor and assume a challenge that might not come, but be prepared if it should occur.

5. Start collecting books for your classroom or school library. Think about how queer texts connect to genre studies or various themes like family, overcoming challenges, friendship, romance, civil rights, and more.

\section{References}

Page, M. L. (2014, April). English/Language Arts teachers' comfort and awareness levels related to LGBT-inclusive literature and curriculum. Paper presented at the Annual Meeting of the American Educational Research Association, Philadelphia, PA.

Page, M. L. (under review) From Awareness to Action: Teacher Attitude and Implementation of LGBT-Inclusive Curriculum in the English/Language Arts Classroom. 
Page, M. L. (2016, November). Unveiling school and community resources of rural sexual minority youth. Paper [to be] presented at the Annual Meeting of the National Council of Teachers of English, Atlanta GA.

Biegel, S. (2010). Right to be out : Sexual orientation and gender identity in America's public schools. Minneapolis, MN: University of Minnesota Press.

Brieze, A., Case Tompkins, J., \& Chernouski, E.B. (2010). Gender studies and queer theory (1970s-present). Retrieved from https://owl.english.purdue.edu/owl/resource/722/12/.

Britzman, D. (1995). Is there a queer pedagogy? Or, stop reading straight. Educational Theory 45(2), 151-165.

Cart, M. \& Jenkins, C.A. (2015). Top 250 LGBTQ books for teens: Coming out, being out, and the search for community. Chicago, IL: Huron Street Press, an imprint of the American Library Association.

Comment, K.M. (2009). "Wasn't she a lesbian?" Teaching homoerotic themes in Dickinson and Whitman. English Journal, 98(4), 61-66.

Curwood, J.S., Schliesman, M., and Horning, K.T. (2009). Fight for your right: Censorship, selection, and LGBTQ literature. English Journal, 98(4), 37-43.

Emert, T. (2013, November). Straight talk about queer young adult literature: Implications for the English classroom. Paper presented at the meeting of National Council of Teachers of English, Boston MA.

GLSEN (2011). Teaching Respect: LGBT-Inclusive Curriculum and School Climate (Research Brief). New York: GLSEN.

Knotts, G., \& Gregorio, D. (2011). Confronting homophobia at school: High school students and the Gay Men's Chorus of Los Angeles. Journal of LGBT Youth 8(1), 66-83. 
Kosciw, J.G., Gretak, E.A., Palmer, N.A., \& Boesen, M.J. (2014). The 2013 National School Climate Survey: The experiences of lesbian, gay, bisexual and transgender youth in our nation's schools. New York: GLSEN.

Ladson-Billings, G. (1995). But that's just good teaching! The case for culturally relevant pedagogy. Theory into Practice 34(3), 159-165.

Lecesne, J. (2012). Aliens among us: Exploring identity and identities in young adult literature. The ALAN Review 39(2), 74-78.

Lent, R. \& Pipkin, G. (2013). Keep them reading: An anti-censorship handbook for educators. New York: Teachers College Press.

Letts, W. (2002). Revisioning multiculturalism in teacher education: Isn't it queer? In R. M. Kissen (Ed.), Getting ready for Benjamin: Preparing teachers for sexual diversity in the classroom (119-131). Lanham, MD: Rowan and Littlefield.

Mayo, C. (2009). The tolerance that dare not speak its name. In A. Darder and R. Torres (Eds.), The critical pedagogy reader: Second edition (pp. 262-273). New York: Routledge.

McLean, M.M. (1997). Out of the closet and onto the bookshelves: Images of gays and lesbians in young adult literature. In T. Rogers \& A. Soter (Eds.), Reading Across Cultures: Teaching Literature in a Diverse Society (pp. 178-198). New York: Teachers College Press.

National Governors Association Center for Best Practices. (2010). Common Core state standards: (English Language Arts standards). Retrieved from http://www.corestandards.org/ELA-Literacy/.

O’Shaughnessy, M., Russell, S., Heck, K., Calhoun, C., \& Laub, C. (2004). Safe space to learn: Consequences of harassment based on actual or perceived sexual orientation and gender 
non-conformity and steps for making schools safer. San Francisco, CA: California Safe Schools Coalition.

Ressler, P. (2005). Challenging normative sexual and gender identity beliefs through Romeo and Juliet. English Journal 95(1), 52-57.

Robinson, J.P. \& Espelage, D.L. (2011). Inequities in educational and psychological outcomes between LGBTQ and straight students in middle and high school. Educational Researcher 40, 315-330.

Robinson, J.P. \& Espelage, D. (2012). Bullying explains only part of the LGBTQ-heterosexual risk disparities: Implications for policy and practice. Educational Researcher, 41(8), 309-319.

Russell, S.T., Kostroski, O., McGuire, J.K., Laub, C., \& Manke, E. (2006). LGBT issues in the curriculum promotes school safety (California Safe Schools Coalition Research Brief No. 4). San Francisco: California Safe Schools Coalition.

Toomey, R.B., Ryan, C., Diaz, R.M., \& Russell, S.T. (2011). High school gay-straight alliances (GSAs) and young adult well-being: An examination of GSA presence, participation, and perceived effectiveness. Applied Developmental Science, 15(4), 175-185.

Winans, A.E. (2006). Queering pedagogy in the English classroom: Engaging with the places where thinking stops. Pedagogy: Critical Approaches to Teaching Literature, Language, Composition, and Culture, 6(1), 103-122.

\section{MORE TO EXPLORE!}


- Teaching Tolerance offers some guidance on considering various elements of school climate related to LGBTQIA students. Find their post at http://www.tolerance.org/lgbtbest-practices

- Need help with titles? The Cooperative Children's Book Center is a great resource. See their list of recommended books with gay and lesbian themes and topics at http://ccbc.education.wisc.edu/books/detailListBooks.asp?idBookLists=446 A list of books with LGBTQIA content compiled from CCBC's Choices (with titles, genres, and themes) can be found at http://personal.morris.umn.edu/ pagem/RecommendedLGBTQReading.pdf.

- Readwritethink's podcast, Episode 13-Gay and Lesbian Characters in Young Adult Literature, can help you think about the ways LGBTQ characters are represented in young adult literature. Go to http://www.readwritethink.org/parent-afterschoolresources/podcast-episodes/lesbian-characters-young-adult-30329.html

- PBS lists resources "designed to aid teachers that are looking for ways to support LGBT students": http://www.pbs.org/newshour/extra/2015/06/teachers-guide-to-lgbt-youthresources/

- Interested in a media literacy unit? Canada's Centre for Digital and Media Literacy specifically addresses representations of queer identities in the media: http://mediasmarts.ca/digital-media-literacy/media-issues/diversity-media/queerrepresentation 